\title{
The antecedents and consequence of functional and dysfunctional conflict in marketing and sales relationships
}

\begin{abstract}
Focusing on the working relationship between Marketing Managers and Sales Managers, our study examines two dimensions of interpersonal conflict: dysfunctional conflict and functional conflict. Drawing on relevant theory, we include three communication variables frequency, bidirectionality, and quality - as antecedents in our structural model. Using these explanatory variables we predict the two conflict dimensions, and in turn, use these same three communication variables, and the two conflict dimensions to predict our ultimate endogenous variable - perceived relationship effectiveness. Overall, our model has high explanatory power, and we find support for nine of the thirteen hypotheses. More specifically, two of the three communication variables - communication quality and bidirectionality significantly impact on both forms of conflict, and relationship effectiveness, though communication frequency only influenced the quality of communication between the Marketing Managers and the Sales Managers. In addition, the variables in our model better predict the levels of functional conflict in the Marketing/Sales relationship than dysfunctional conflict. Finally, an important new finding in this research is that the overall level of dysfunctional conflict between these two functional managers is relatively low, while functional conflict is high.
\end{abstract}

Keywords: Cross-functional relationships, functional and dysfunctional conflict, perceived relationship effectiveness, marketing/sales relationships. 


\section{Introduction}

Cross-functional integration requires employees from different departments to communicate and interact, in order to exchange work, resources, and assistance (Ruekert \& Walker, 1987a). These repeated interactions influence the development of "cross-functional relationships" (CFRs). CFRs are important to the efficient operation of firms, and have strong theoretical and practical links to internal marketing (e.g., Ballantyne, 1997), market orientation (e.g., Kohli \& Jaworski, 1990), and Porter's (1985) value chain. Marketing's CFRs are particularly important for example, during new product development, as they can facilitate the development of successful new products (e.g., Souder, 1981), and hence have implications for portfolio management, medium to long-term cash flows, and long-term survival (Cooper, 1996; Crawford \& DiBenedetto, 2003). Similarly, customer relationship management depends on good integration between the Marketing and Information Technology functions (Ryals \& Payne, 2001; Winer, 2001). The performance of individual managers, departments, and the firm itself can therefore depend on the effectiveness of Marketing's CFRs, hence these CFRs are of significant academic and managerial importance (Houston et al., 2001).

The context of this research is the CFR between Marketing Managers and Sales Managers, and we adopt this focus for various reasons. First, it is among the most important of marketing's CFRs, and yet remains one of the least explored in the academic literature (Dewsnap \& Jobber, 2000). Second, the Marketing/Sales CFR is vital because Sales implements Marketing's strategies at the operational level (Strahle et al., 1996).

Our paper focuses on factors which promote "effective” Marketing/Sales CFRs, that is, those with low dysfunctional conflict, and high perceived relationship effectiveness. Many disciplines acknowledge the importance of conflict in understanding team effectiveness (for a synthesis of current models of conflict, see Jehn, 1997), and importantly, a growing body of literature suggests that not all conflict is dysfunctional (De Dreu \& Weingart, 2003; Jehn, 
1995), and that under some circumstances, conflict can be beneficial (Amason, 1996). The purpose of our research is therefore to test the effects of three different forms of communication on three key endogenous variables - dysfunctional conflict, functional conflict, and perceived relationship effectiveness.

Our study differs from previous research on intraorganisational conflict in several ways, and makes a number of important contributions. First, although conflict has been studied at various levels of analysis (e.g., SBUs, departments), we focus on the individual level, and examine interpersonal conflict. This contrasts with the key marketing CFR studies which have examined interdepartmental conflict (Barclay, 1991; Maltz \& Kohli, 2000; Menon et al., 1996; Morgan \& Piercy, 1998).

Second, recent organizational studies suggest that interpersonal conflict has multiple dimensions (e.g., Reid et al., 2004). Here, we focus on two of these dimensions - functional and dysfunctional conflict, and by examining these dimensions, we differ from the majority of existing research which focuses solely on dysfunctional conflict. Though Menon et al. (1996) examined antecedents and consequences of interdepartmental functional conflict, we could not locate any studies that have done this at the individual level. Furthermore, although the literature contains much theoretical discussion of functional conflict (e.g., Schwenk, 1989; Tjosvold, 1985), few studies have measured this construct, or modeled its antecedents or consequences. Our study therefore adds to the scant evidence on this important construct.

Third, while there is a significant body of theory linking communication and conflict, few studies in management or marketing have empirically tested the relationship between these constructs in peer manager relationships. So by linking three communication variables frequency, bidirectionality, and quality - to both dysfunctional and functional conflict, we add to this sparse literature. 
Fourth, our focus on the Marketing/Sales CFR provides empirical evidence in an area where the literature is mostly anecdotal, conceptual, or normative. By quantifying the levels of dysfunctional and functional conflict, and by identifying the antecedents with the most explanatory power, we begin to fill this gap in the literature. Last, we believe that despite our narrow research context, our findings are generalisable to other marketing CFRs (e.g., Marketing/IT), and to non-marketing CFRs (e.g., Manufacturing/Purchasing).

Our paper is structured as follows. First, we present our conceptual framework in which we define the key constructs and justify their inclusion in our model. Next we specify a structural model and develop our hypotheses. We then describe our research methods, and report the results of our empirical tests. We conclude by discussing the implications of our research, its limitations, and possible topics for future research.

\section{Conceptual framework}

In developing our model, we draw on the interaction approach as our main theoretical perspective. This framework has been used in many important studies of marketing's relationships (e.g., Moenaert et al., 1994; Ruekert \& Walker, 1987a), and is based on exchange theory (Blau, 1964) and game theory (Axelrod, 1984) and focuses on understanding how factors such as communication behaviours predict satisfaction, performance, and relationship continuity in various contexts, e.g., buyer-seller and channel relationships (Anderson \& Narus, 1990; Morgan \& Hunt, 1994; Moorman et al., 1993), and crossfunctional relationships (e.g., Ruekert \& Walker, 1987a).

Drawing on this framework, our model uses three communication variables communication frequency, bidirectionality, and communication quality - to predict functional conflict, dysfunctional conflict, and perceived relationship effectiveness. These three explanatory variables are apposite because the current state of a CFR is the result of an 
ongoing series of interactions between functional managers (Fisher et al., 1997; Johlke et al., 2000). Further support for including these variables is provided by Johnson (1993), who argued that communication is a primary means by which personnel process information, reduce ambiguity, and coordinate their actions.

An important new aspect to our conceptualization is that we treat bidirectional communication and communication frequency as antecedents to communication quality. Last, we treat dysfunctional and functional conflict as mediating variables in order to test their impact on relationship effectiveness.

[Insert Figure 1]

\subsection{Endogenous variable: perceived relationship effectiveness}

Our ultimate endogenous variable, perceived relationship effectiveness, is drawn from Van de Ven (1976), and we define this construct in terms of how worthwhile, equitable, productive, and satisfying the Marketing Manager perceives his/her working relationship with the Sales Manager to be during a specific cross-functional project. We chose this psychosocial outcome because: (1) past studies of effective working relationships have also focused on subjective outcomes (e.g., Anderson \& Narus, 1990); and (2) objective measures of effectiveness (e.g., sales volume) may not accurately reflect the quality of a relationship due to confounding factors such as long sales cycles (Smith \& Barclay, 1997).

\subsection{Key mediating variables: dysfunctional and functional conflict}

A contemporary view amongst various streams of literature is that conflict has multiple underlying dimensions. Its original conceptualization is the dysfunctional form (cf. Pondy, 1967), which is associated with negative outcomes including the distortion and withholding of 
information to the detriment of others within the organization, hostility, and distrust during interactions (Thomas, 1990; Zillman, 1988), opportunistic behavior (Barclay, 1991), information gatekeeping (Jaworski \& Kohli, 1993), and the creation of obstacles to decision making (Ruekert \& Walker, 1987b).

Dysfunctional conflict is believed to reduce team performance and member satisfaction, because of the associated tension and antagonism, and can distract people from their task performance (De Dreu \& Weingart, 2003). Accordingly, we define the construct in the conventional sense, as being unhealthy, and associated with dysfunctional behaviours, dissatisfaction, and poor individual and/or group performance.

In contrast, conflict can also have a functional form (Amason, 1996), and the consultative interactions and useful give and take typical of functional conflict are believed to have beneficial effects in peer manager relationships. Where functional conflict is present, people feel free to express their opinions, and to challenge others' ideas, beliefs, and assumptions (e.g., Baron, 1991; Cosier, 1978; Schwenk, 1989; Tjosvold, 1985). Functional conflict can be considered an antidote to "groupthink" where feelings of solidarity and loyalty to a decisionmaking group override the imperative to logically and realistically evaluate all options (Filley, 1970). Accordingly, we define functional conflict as a constructive challenging of ideas, beliefs, and assumptions, and respect for others’ viewpoints even when parties disagree.

\subsection{Explanatory variables: communication quality, frequency, and bidirectionality}

We include communication quality because various studies of the Marketing/R\&D CFR during product development (e.g., Gupta et al., 1986; Gupta \& Wilemon, 1988) suggest that the quality of communication provided by Marketing to R\&D can influence the perceived competence of Marketing Managers. The provision of high quality information allows interdependent managers to better achieve individual and joint goals (e.g., Gupta \& Wilemon, 
1988; Jassawalla \& Sashittal, 1998). Therefore high communication quality should be associated with positive outcomes, such as lower dysfunctional conflict, higher functional conflict, and higher relationship effectiveness. Consistent with Souder and Moenaert's (1992) conceptualization, communication quality is defined as how credible, understandable, relevant, and useful the information provided by the Sales Manager was for the Marketing Manager’s task completion.

To provide a multidimensional view of cross-functional communication, we also examine communication frequency and bidirectionality. Communication frequency is widely regarded as a key variable in many contexts, including channel relationships (e.g., Mohr \& Nevin, 1990), and CFRs (e.g., Ruekert \& Walker, 1987a). Here we define communication frequency as the intensity of one-way information flow through media such as e-mail, memos, and face-to-face meetings (Morgan \& Piercy, 1998).

We also include bidirectional communication because three recent studies have shown that bidirectionality is at least as important in CFRs as communication frequency (Dawes \& Massey, 2005; Fisher et al., 1997; Johlke et al., 2000). Consistent with Fisher et al. (1997), we define bidirectionality as the degree to which communication between Marketing Managers and Sales Managers is a two-way process.

\section{Hypotheses development}

\section{Effects of communication frequency}

Interaction theory suggests that frequent communication can have both dysfunctional and functional effects, therefore, no clear predictions can be made from this theory alone. Some scholars argue that frequent cross-functional communication is beneficial, allowing personnel to become conversant with, and better understand the language and jargon of their counterparts (e.g., Maltz, 1996). Similarly, more frequent communication can reduce the 
uncertainty associated with an activity, facilitate performance (Daft \& Lengel, 1984; Galbraith, 1977), and lead to mutual understanding and better rapport within teams (Menon et al., 1999). Some empirical evidence supports these claims, as frequent communication has been linked to project success, cross-functional integration, improved coordination, better understanding of others' information requirements, and relationship effectiveness (Dougherty, 1992; Ruekert \& Walker, 1987a; Souder, 1981). These studies suggest that frequent communication should be associated with positive outcomes such as low dysfunctional conflict, high functional conflict, and high perceived relationship effectiveness.

Conversely, other studies link frequent communication with negative outcomes. Maltz and Kohli (1996) for example found that beyond a certain threshold, frequent peer manager communications are perceived to be low quality and dysfunctional. Similarly, Ruekert and Walker (1987a) found that higher "interaction flows" between Marketing and R\&D, and Marketing and Accounting were associated with increased dysfunctional conflict. Recent work by Dawes and Massey (2005) supports these studies, finding that frequent communication in the Marketing/Sales CFR is positively associated with dysfunctional conflict.

Despite the mixed predictions from theory and the inconsistent empirical evidence, we posit that more frequent communication between Marketing Managers and Sales Managers will lead to greater dysfunctional conflict. We argue this because the more frequent the interactions, the greater the opportunity for this conflict to arise. Recall that we conceptualize communication frequency as one-way, frequent interaction, rather than two-way, collaborative interaction. Also, our sample consists of middle to senior-level peer managers, and we expect such managers will respond negatively to high frequency communication, and be antagonized by such communication behaviors. 
Consistent with this, we argue that high communication frequency will be associated with lower communication quality, less functional conflict, and reduced relationship effectiveness. As Maltz and Kohli (1996) found, high frequency communication is likely to be perceived as low in quality, and therefore unlikely to have sufficient information content to stimulate functional conflict. Further, having received low quality information, peer managers are unlikely to consider this as a reasonable basis upon which to conclude that their CFR with the sender is effective. We therefore hypothesize:

H1a: Higher communication frequency leads to higher dysfunctional interpersonal conflict.

H1b: Higher communication frequency leads to lower functional interpersonal conflict.

H1c: Higher communication frequency leads to reduced communication quality.

H1d: Higher communication frequency leads to lower perceived relationship effectiveness.

\section{Effects of bidirectional communication}

Our hypotheses regarding the effects of bidirectional communication are guided by recent research in various contexts. Work on interfirm communications (e.g., Mohr et al. 1996) treats bidirectionality as an underlying dimension of a second-order factor - "collaborative communication.” Their results reveal that collaborative communication has a strong positive effect on relationship satisfaction, a state of low dysfunctional conflict. Similarly, Jablin's (1979) study of supervisor-subordinate communications found that bidirectional communication leads to more effective relationships. 
In the CFR literature, a number of studies suggest that bidirectionality reduces ambiguity, facilitates dialogue, helps clarify and improve dyadic communications, and increases relationship effectiveness (Fisher et al., 1997; Johlke et al., 2000). Similarly, others argue that where there are barriers to communication (e.g., there is low bidirectional communication), this can create confusion, misunderstanding, and reduce the opportunity for healthy constructive discussion (Barclay, 1991; Menon et al., 1996; Menon \& Varadarajan, 1992). In their recent study of Marketing/Sales CFRs, Dawes and Massey (2005) found that of all constructs in their model, bidirectional communication had the single strongest effect in reducing dysfunctional conflict. They argue that one explanation for this effect might be that bidirectionality is a collaborative, consultative form of communication. In sum, these studies suggest that collaborative forms of communication such as bidirectionality are likely to assist in building effective CFRs, and be associated with lower dysfunctional conflict, higher functional conflict, and higher relationship effectiveness. We therefore hypothesize:

H2a: Higher bidirectionality leads to lower dysfunctional interpersonal conflict.

H2b: Higher bidirectionality leads to higher functional interpersonal conflict.

H2c: Higher bidirectionality leads to higher perceived relationship effectiveness.

Dougherty (1992) suggests that organizational routines involving interdepartmental feedback and elaboration can improve peer managers' perceptions of others' inputs. Therefore high bidirectionality should be associated with increased communication quality. Similarly, Wheelwright and Clark (1992) noted that bidirectionality can help improve the quality of dyadic communication by increasing clarity, and reducing ambiguity. Further support is also 
provided by Fisher et al. (1997) who found that bidirectional communication between Marketing Managers and Engineering Managers, during product development projects, correlated strongly with information use. Accordingly, managers with a high propensity to use information provided are likely to perceive that information to be of high quality. We therefore predict that bidirectional communication will be positively associated with the provision of quality information to peer managers. Accordingly we hypothesize:

H2d: Higher bidirectionality leads to greater communication quality.

\section{Effects of communication quality}

Support for our hypotheses regarding communication quality exists in the management and psychology literature. Some management theorists (e.g., Daft \& Weick, 1984) conceive of firms as information processing systems, and managers as boundary spanners who act as nodes of uncertainty absorption (March \& Simon, 1958). Consistent with this, in the psychology literature the "information processing perspective" on conflict suggests that as a person's cognitive load increases, their cognitive system shuts down, information processing is impeded, and team performance is likely to suffer (Carnevale \& Probst, 1998). Hence poor quality information is likely to adversely affect a manager's ability to absorb uncertainty, and to process information. Poor quality information should therefore be associated with higher dysfunctional conflict, and lower functional conflict with managers who provide such information. Maltz and Kohli (1996) provide some support for these propositions, finding that poor quality communications between departments are dysfunctional, as they lower the receiver's trust in the sender. Similarly, Menon et al. (1999) found that communication quality is positively associated with the creative development of marketing strategy by cross- 
functional teams. We therefore expect communication quality to be associated negatively with dysfunctional conflict, and positively with functional conflict. Accordingly, we hypothesize:

H3a: Higher communication quality leads to lower dysfunctional interpersonal conflict.

H3b: Higher communication quality leads to higher functional interpersonal conflict.

Consistent with Moenaert et al. (1992), we conceptualize communication quality as the perceived relevance and utility of information provided for the task at hand. Here, this relates to information provided to the Marketing Manager by the Sales Manager on a joint project. While Moenaert et al. (1992) did not investigate the effects of communication quality on relationship effectiveness, they did note that this construct correlates positively with innovation success (Cooper, 1979; Zirger \& Maidique, 1990). Where peer managers are involved in successful projects, they are likely to perceive their CFRs to be effective. Other work has found a positive association between communication quality and cross-functional integration (Menon et al., 1999). Using these findings as support, we therefore hypothesize:

H3c: Higher communication quality leads to higher perceived relationship effectiveness.

\section{Effects of dysfunctional conflict}

As noted, a significant body of literature has linked dysfunctional conflict to negative psychosocial and task outcomes. Jaworski and Kohli (1993) for example, found that higher conflict was associated with reduced market orientation, intelligence dissemination, and organizational responsiveness. Similarly, Menon et al. (1996) found that dysfunctional conflict reduces the quality of marketing strategy formulation and implementation, while 
Ruekert and Walker (1987a) found that high dysfunctional conflict was associated with lower perceived relationship effectiveness. Accordingly, managers in CFRs with high dysfunctional conflict are likely to perceive their relationships to be ineffective. We therefore hypothesize:

H4a: Higher dysfunctional conflict leads to lower perceived relationship effectiveness.

\section{Effects of functional conflict}

While few studies have examined the psychosocial effects of functional conflict, a number of them suggest that it is associated with improved task outcomes. Menon et al. (1996) for example, found that functional conflict between Marketing and senior management significantly improved the quality of strategy formulation and implementation. Functional conflict within relationships involves consultative interactions, mutual respect, and useful give and take. Therefore, even if there are disagreements, discussions focus on issues rather than on people, and such discussions occur in an atmosphere in which people feel comfortable to raise dissenting viewpoints. In such circumstances, functional conflict can stimulate careful consideration of assumptions and alternatives, which in turn, can improve the quality of group decisions (Cosier \& Schwenk, 1990). Therefore, where functional conflict is present in a CFR, peer managers are more likely to consider their relationship to be effective. Accordingly, we put forward our final hypothesis:

H4b: Higher functional conflict leads to higher perceived relationship effectiveness.

\section{Method}

In order to provide a common general context for the responding Marketing Managers, they were asked to focus on a specific, major cross-functional project in which both they and 
the Sales Manager, along with staff from at least two other functional areas, were heavily involved during the previous 18 months. Most projects $(55.7 \%)$ related to new product development, while the remaining $44.3 \%$ covered a wide range of activities including: promotion and public relations (19.6\%), business development activities (10.3\%), internal review of strategy and structure (5.1\%), and miscellaneous projects (9.3\%). On average, 4.06 functional units were involved in the projects, with an average of 13.81 people involved, and a mean budget of $\$ 1.031$ million.

\subsection{Data collection}

Using a pretested, self-administered, mailed questionnaire, data were collected from firms in Australia which were selected from a proprietary database purchased from a list broker. This database consisted of 1,103 firms, where the primary selection criterion for a firm's inclusion was that it must have a separate and identifiable Marketing Manager or senior Marketing executive, plus a Sales Manager, or senior Sales executive. Data were sought only from Marketing Managers.

However, due to expected inaccuracies in the database, it was inspected to remove firms which did not meet the primary qualifying criterion. So persons with dual responsibilities (e.g., "Sales \& Marketing Managers”) were deleted from the sampling frame, as were the firms in which one person held the titles of Sales Manager and Marketing Manager simultaneously. In addition, managers with job titles with no relevance to the study were deleted, leaving a qualified sampling frame of 501 firms throughout Australia.

After a second-wave mailout, a total of 113 questionnaires were returned. However, ten of these were deemed unusable because the respondents' job titles suggested that they were not part of the relevant population (e.g., they were the "Sales and Marketing Manager"). Moreover, in order to identify reasons for non response, a stamped, self-addressed postcard 
was attached to each follow-up questionnaire. In total, 53 postcards were returned and the reasons for not completing the questionnaire were: (a) 43.4\% said it was company policy not to fill out this type of questionnaire; (b) $11.5 \%$ felt that the information required was too sensitive; (c) 9.4\% said there was nobody in their firm with the term "Sales" in their title; (d) 7.5\% said that they had very little interaction with the "Salespeople" in the firm; and (e) 3.8\% indicated that they had only been with the firm for a short while and, as a result, they didn't know the Sales Manager well enough.

After allowing for the 53 organisations which had returned the postcards, we were left with 103 questionnaires from an eligible 448 organizations (effective response rate $=23 \%$ ). However, inspection of three of the questionnaires revealed that the respondents did not answer any of the questions relating to the constructs in our model. Accordingly, we were left with usable responses from exactly 100 Marketing Managers (effective response rate = $22.3 \%)$. Though this rate is relatively low, it is comparable to the $19.7 \%$ overall response rate of Homburg et al. (1999), who obtained data from Marketing Managers regarding Marketing's influence within the firm. Moreover, our response rate is very similar to that of Dawes and Massey (2005), who collected data from Sales Managers in Australia and the UK. This latter study, which had an overall response rate of 20.3\%, examined the sensitive topic of the antecedents of marketing's dysfunctional conflict with sales.

The final sample of firms revealed good diversity. Specifically, goods-producers accounted for $45 \%$ of the responding organizations; service-providers for $12 \%$, and $44 \%$ sold both goods and services. In terms of market type, $42 \%$ were in business markets, $27 \%$ in consumer markets, while $31 \%$ sold to both types of market. Finally, the average firm size was 557 employees.

4.2. Evaluating the quality of the data collected. 
Tests of nonresponse bias indicated no significant differences between early and late respondents in terms of five variables. Three of these relate to the individual - positional level, relative level of education, and the Marketing Managers' vocational sales experience. The remaining two variables were organizational variables - proportion of goods versus service firms and markets served.

The Marketing Manager had worked with the Sales Manager for an average of 3.5 years, which suggests they were knowledgeable about the issues covered in this research. In other words, our key informants were competent to provide the data required.

\subsection{Measurement}

One formative multi-item measure was used (communication frequency), and five reflective multi-item measures (bidirectional communication, communication quality, dysfunctional conflict, functional conflict, and perceived relationship effectiveness). Principal components analysis revealed that all reflective multi-item constructs were unidimensional. As our sample was relatively small $(n=100)$ we did not conduct confirmatory factor analysis because of the likelihood of nonconvergence and improper solutions (Gerbing \& Anderson, 1988). Instead we used partial least squares (PLS) to estimate our measurement and structural models.

Analysis of the PLS “inner” (measurement) models revealed that most of the items used to capture the reflective constructs were adequate indicators of those latent variables. There were however two exceptions. First, one item measuring bidirectional communication was deleted because it loaded weakly on the latent variable. Second, the standardized factor loadings for three of the functional conflict items were low, suggesting that they did not account for a sufficient amount of variance in the underlying construct. In such cases these items add very little to the explanatory power of the measurement model, and if not omitted from the 
analysis, could attenuate (and therefore bias) the estimates of the path coefficients in the structural model (Hulland, 1999). Accordingly, we deleted the three low-loading items from our functional conflict measure in order to improve the construct validity.

\section{[Insert Table 1]}

Convergent validity was established in two ways. First, the t-values from the PLS were examined for each item, and all were statistically significant (Anderson \& Gerbing, 1988). Second, the average variance extracted (AVE) for each construct was calculated, and all exceeded .50. The AVE for dysfunctional conflict for example was .61, while that of functional conflict was .70.

Of particular importance was establishing discriminant validity between two key pairs of constructs - the two communication dimensions (bidirectional communication and communication quality), and the two conflict dimensions (functional and dysfunctional conflict). We therefore tested discriminant validity in two ways. First, all ten pairs of reflective measures were tested using Fornell and Larcker's (1981) criterion, that the AVEs for each pair of reflective constructs should be greater than the square of the correlation between those constructs. Using this criterion discriminant validity was established not only between the communication dimensions, and the conflict dimensions, but between all pairs of reflective constructs in our model. In addition, and as shown in Table 2, the square root of the average variance extracted for each reflective construct is greater than all corresponding correlations (Fornell \& Larcker, 1981), indicating that each construct is more highly correlated with its measure, than with any of the other model constructs.

Reliability analysis revealed that the composite reliability and alpha coefficients for all of the scales are adequate. The composite reliability of functional conflict for example is .88, and 
$\alpha=.80$, while the composite reliability of dysfunctional conflict $=.86$, and $\alpha=.79$. A full description of the final measures and their associated statistics are shown in the Appendix.

\section{Results}

\subsection{Descriptive findings}

As shown in Table 2, the descriptive statistics reveal that, on average, our responding Marketing Managers enjoy a good relationship with their counterpart Sales Managers. Specifically, the level of dysfunctional conflict is low, mean $=2.77$ out of 7 , where low

numbers indicate low dysfunctional conflict. The standard deviation however, reveals considerable variation in the level of conflict (s.d. $=1.47)$. The low level of dysfunctional conflict we observe therefore contrasts with the moderately high levels of conflict observed by Maltz and Kohli (2000). They report levels of dysfunctional conflict on a 5-point scale, where low numbers indicate low conflict, specifically, mean $=2.76$ between Marketing and $R \& D$, mean = 2.72 for Marketing and Manufacturing, and mean = 2.57 for Marketing and Finance. However, our results here are consistent with Dawes and Massey (2005), who used a sample of Sales Managers to report on their relationship with their counterpart Marketing Manager, and report a mean for dysfunctional conflict between these managers $=2.76$ on a seven-point scale. In addition, we find a fairly high level of functional conflict in our observed CFRs (mean $=5.43$, s.d. $=1.24)$, where low numbers indicate low functional conflict. Last, the overall level of relationship effectiveness is high $($ mean $=5.09$, s.d. $=1.66)$.

Overall, these results show that dysfunctional conflict between Marketing Managers and Sales Managers during the focal projects is fairly low, and that functional conflict and relationship effectiveness is reasonably high. Our findings here, coupled with those of Dawes and Massey (2005) therefore suggest that the conventional wisdom of the 1980s/90s, in which 
Marketing's relationship with Sales is viewed as being generally problematic (see Dewsnap and Jobber’s (2000) literature review), may no longer accurately reflect the current situation.

[Insert Table 2]

\subsection{Model testing}

PLS was used to estimate our structural model, and was considered appropriate for a number of reasons: (1) our final sample size is relatively small $(n=100),(2)$ we use both formative and reflective measures, (3) we do not make any assumptions about multivariate normality, and (4) our primary concern is prediction of our endogenous variables (Chin, 1998; Diamantopolous \& Winklhofer, 2001; Fornell \& Bookstein, 1982).

In order to establish the stability and significance of our parameter estimates, we computed the t-values using 100 bootstrap samples. As shown in Table 2, nine of the thirteen hypotheses were supported. The $\mathrm{R}^{2}$ for perceived relationship effectiveness is .826 , suggesting that our model explains $82.6 \%$ of the variance in this endogenous variable. Similarly, the $\mathrm{R}^{2}$ for functional conflict was high (.573), though the result for dysfunctional conflict was lower (.324). Finally, the $\mathrm{R}^{2}$ for communication quality was .637. Together these results suggest that the model has good explanatory power, and that the communication behaviours of Marketing Managers and Sales Managers have a significant impact on both forms of interpersonal conflict, and relationship effectiveness.

\section{[Insert Table 3]}

\subsection{Tests of hypotheses}

As depicted in Table 3, communication frequency had no effect on dysfunctional conflict (H1a), functional conflict (H1b), or perceived relationship effectiveness (H1d). However, we found that communication frequency was associated with an increase in communication 
quality $(\mathrm{H} 1 \mathrm{c})$, (beta $=.220 ; \mathrm{p} \leq .01)$. In contrast, all four hypotheses concerning bidirectional communication (H2a, H2b, H2c, and H2d) were significant. Specifically, bidirectionality was found to be negatively associated with dysfunctional conflict (beta $=-.361 ; \mathrm{p} \leq .01$ ) but positively associated with functional conflict (beta $=.225 ; \mathrm{p} \leq .05$ ), perceived relationship effectiveness (beta $=.180 ; \mathrm{p} \leq .01$ ), and communication quality (beta $=.660 ; \mathrm{p} \leq .001$ ).

Moreover, we found good support for all three hypotheses concerning communication quality (H3a, H3b, and H3c). Specifically, and as expected, we found that increased communication quality decreased dysfunctional conflict (beta $=-.269 ; \mathrm{p} \leq .05$ ). In contrast, but as predicted, we found that increased communication quality increased functional conflict (beta $=.537 ; \mathrm{p} \leq .001)$ and relationship effectiveness (beta $=.382 ; \mathrm{p} \leq .001$ ).

Finally, we obtained strong support for our last two hypotheses. With respect to H4a, we found that increased dysfunctional conflict led to decreased perceived relationship effectiveness (beta $=-.271 ; \mathrm{p} \leq .001$ ). And, as expected for $\mathrm{H} 4 \mathrm{~b}$, we found that increased functional conflict positively impacts on perceived relationship effectiveness (beta $=.223$; $\mathrm{p} \leq$ $.001)$

\section{Discussion}

\subsection{Theoretical implications}

The study tests a model explaining variations in the levels of dysfunctional conflict, functional conflict, and perceived relationship effectiveness in the Marketing/Sales CFR. The data used for model testing was obtained from Marketing Managers, who were asked to focus on their working relationships with Sales Managers.

Overall, the model had high explanatory power in predicting perceived relationship effectiveness and functional conflict, but was only moderately successful in explaining 
dysfunctional conflict. Our analysis revealed that the two communication variables with the most explanatory power were communication quality, and bidirectionality. All seven hypotheses relating to these constructs were significant, and in the hypothesized direction. This contrasts with communication frequency where only one of the hypotheses was significant.

Communication quality had the single strongest positive effect on functional conflict, and the second strongest negative effect on dysfunctional conflict. High quality information is the basis for effective decision-making, and under conditions of uncertainty, high quality information helps managers evaluate all options, and challenge ideas and assumptions, that is, engage in behaviours indicative of functional conflict. Conversely, where communication is poor in quality, this may frustrate peer managers, and lead to dysfunctional conflict with those providing that information (Robbins, 1990). In addition, we found that communication quality had the single strongest effect on perceived relationship effectiveness. This finding is unsurprising, given that high quality information should facilitate better joint decisionmaking, and under these conditions peer managers will be more likely to perceive their relationship to be effective.

Our results for bidirectional communication also support this line of reasoning. Bidirectional communication is a consultative, collaborative form of communication, involving reciprocity, and consistent with this, our results show that bidirectionality has the strongest negative effect on dysfunctional conflict, and the second strongest positive effect on functional conflict. The two-way give and take of bidirectional communication, coupled with high quality cross-functional communication, therefore seem the ideal vehicles with which to promote constructive debate and stimulate functional conflict. Similarly, the strong negative association between bidirectionality and dysfunctional conflict is probably due to the ability of this two-way communication to clarify misunderstandings, and increase managers' 
knowledge of others' issues and priorities. Our results support this argument, and are consistent with Fisher et al. (1997), who found that bidirectional communication was associated with higher levels of perceived relationship effectiveness, a state of low dysfunctional conflict.

In contrast to the two potential predictions of interaction theory, we find that high frequency communication has neither a positive or negative effect on functional conflict, dysfunctional conflict, or relationship effectiveness. We did however find that communication frequency is positively associated with communication quality. This finding therefore supports studies such as Maltz (1996) and Menon et al. (1999), which found that more frequent communication helps managers better understand the language and jargon of counterpart managers in other functional areas. This in turn may help increase the quality of communication exchanged between these managers.

Our results are therefore inconsistent with Maltz and Kohli (1996), who found that low frequency communication may be functional, but at high frequencies may become dysfunctional, by reducing the perceived quality of information received. Our findings support the view that communication frequency can help Marketing/Sales CFRs by increasing the quality of information exchanged between these peer managers. This is important because of the strong effects that communication quality has in decreasing dysfunctional conflict, and increasing both functional conflict and relationship effectiveness.

The results we report here however, contrast with Dawes and Massey (2005), who found that communication frequency led to an increase in dysfunctional conflict. One possible explanation for this may lie in differences in the samples. In this current study the respondents were Marketing Managers, rather than Sales Managers as was the case with Dawes and Massey (2005). It is possible that the Marketing Managers in our study more value frequent communication from their counterpart Sales Manager. Sales Managers are a key source of 
information on products, markets and customers, hence it is likely that Marketing Managers will highly value regular updates on these issues. In contrast, the Sales Managers in Dawes and Massey's (2005) study did not appear to value frequent communication from the Marketing Manager, possibly because they considered these communications to be unimportant to their operations. In short, there may be an asymmetry in this CFR regarding the value each manager places on frequent communication with their counterpart manager.

A significant theoretical implication of our findings, particularly when examined in conjunction with the mixed results from studies in the extant literature, is that cross-functional communication within organizations is a complex phenomenon. Even a relatively "simple" construct such as "communication frequency" can have zero effects, such as we observed in this current study for three of our four hypotheses, it can have functional effects (e.g., Menon et al., 1999), or dysfunctional effects (e.g., Dawes and Massey, 2005). The strength and direction of these effects seem to vary depending on factors such as the absolute frequency of communication (e.g., Maltz and Kohli, 1996), or the context of the study, for example, whether Sales Managers or Marketing Managers are used as respondents. This can be seen in the results reported here, in which Marketing Managers are the respondents, compared with the results reported by Dawes and Massey (2005) in which Sales Managers were the respondents. Therefore, a good deal more research is required before any robust positive or normative theories regarding cross-functional communication frequency can emerge.

The effects of dysfunctional and functional conflict on relationship effectiveness were as expected. Consistent with previous studies (e.g., Jaworski \& Kohli, 1993; Menon et al., 1996; Ruekert \& Walker, 1987a), our results show that dysfunctional conflict has detrimental effects on CFRs. This is important because CFR effectiveness is positively associated with task performance, and so unwanted psychosocial outcomes such as high dysfunctional conflict can have serious flow-on effects. Conversely, we found that functional conflict had a strong 
positive impact on relationship effectiveness. This is an important new finding and consequently ours is one of a handful of studies to empirically establish the positive effects of functional conflict on cross-functional outcomes. Thus, we corroborate the existing theory and the very limited empirical evidence on the benefits of functional conflict to project groups, and to organizations as a whole.

Our final theoretical implication concerns the wider applicability of our conceptual model. While our model was tested in the context of Marketing/Sales CFRs, we believe that the issues examined, i.e., the effects of communication behaviors on conflict and relationship effectiveness are generalisable to other CFRs. We believe this because the CFRs we examined have important similarities with CFRs in other firms, and other CFRs within the same firm.

First, the respondents’ firms are structurally similar, i.e., functionally specialised, with separate Marketing and Sales units. Such firms contain a wide range of CFRs, of which the Marketing/Sales CFR is only one. At this early stage of theory development and research into the Marketing/Sales CFR, there are no strong theoretical or empirical reasons to suspect that this CFR is fundamentally different to any other CFR within these firms.

Second, and consistent with the previous point, these CFRs are enacted between managers who are highly interdependent, and need to work together on strategic issues, major projects, and on day-to-day operations, regardless of the functional designation of those managers.

Third, our study focuses on the development and maintenance of relationships between peer managers, and while the context of our study is Marketing and Sales, the constructs examined in our model are not unique to Marketing/Sales CFRs. We therefore believe that the findings we present have a broader relevance than our current research context. 


\subsection{Managerial implications}

Our results have implications for senior managers of firms who wish to improve CFRs between Marketing Managers and Sales Managers. A key issue for managers to consider is that not all forms of cross-functional communication are effective. Contrary to the interactionist perspective, and conventional wisdom, mere frequency of communication is inadequate to reduce dysfunctional conflict, or increase functional conflict and relationship effectiveness between functional managers. In the context of Marketing/Sales CFRs, more communication does not always mean better communication, however, it does appear to help improve the quality of communication between these managers.

When formalizing the required interactions between Marketing Managers and Sales Managers, senior management should therefore place less emphasis on the importance of frequency of cross-functional communication, except where the communication exchanged is manifestly of high quality, i.e., useful to the receiving manager. Our results strongly suggest that senior managers should encourage more collaborative forms of communication such as bidirectionality in the communication behaviors of Marketing Managers and Sales Managers. This could be achieved in various ways, such as the regular, formal exchange of reports between the two managers, or encouraging more face-to-face interaction between those managers. Marketing Managers could for example, be required to spend a certain percentage of their time on the road with the Sales Manager.

Importantly, senior management also need to ensure that the quality of information flowing between the two managers is high, given that communication quality has powerful effects in reducing dysfunctional conflict, and increasing both functional conflict and relationship effectiveness. A key aspect of this would be to precisely identify the information needs of each manager, and to establish mechanisms by which valued information is exchanged regularly. Similarly, encouraging more bidirectionality in communication flows 
can also have important effects on the CFR by helping reduce dysfunctional conflict, and increasing both functional conflict and relationship effectiveness.

Finally, while we found a fairly strong negative association between dysfunctional conflict and relationship effectiveness, senior managers should not focus only on employing strategies to reduce dysfunctional conflict. Instead they could use a two-pronged approach, by simultaneously attempting to decrease dysfunctional conflict, and stimulate functional conflict. The means by which these two objectives can be achieved are revealed in our research, and entail encouraging more bidirectional communication, and increasing the quality of communication exchanged between functional managers. Senior managers should also seek to direct cross-functional communications towards task issues, and deflect discussions away from personal issues, to encourage functional conflict, and mitigate dysfunctional conflict.

\section{Limitations and directions for future research}

A major limitation of our research is that we rely on cross-sectional data to draw inferences regarding relationships which develop, and are enacted over time. Future research could utilize a longitudinal research design to investigate these important phenomena. Another limitation relates to the data being restricted to Marketing Managers’ perceptions, and our findings here, combined with those of Dawes and Massey (2005) suggest that these may differ from those of their counterpart manager in Sales. Future research should therefore examine this relationship by using data obtained simultaneously from both Sales Managers and Marketing Managers within the same firm.

In addition, our findings add weight to the view that variables such as communication frequency have quite different effects in different situations. For example, these effects seem to vary depending on the absolute frequency of communications, and also in different contexts, e.g., the nature of the respondent. These effects may even differ across various types 
of cross-functional work, e.g., complex new product development projects versus day-to-day operational issues. Future research could therefore examine these contextual differences to provide a better understanding of the differential effects of communication frequency.

Last, while we adopted a multidimensional view of communication between these peer managers in this study, there are a range of other communication variables that may be salient in CFRs. Future research could for example look at other communication variables such as the mode, content, and formality of their communications. 


\section{References}

Amason, A. C. (1996). Distinguishing the effects of functional and dysfunctional conflict on strategic decision making: Resolving a paradox for top management teams. Academy of Management Journal, 39(2),123-148.

Anderson, J. C., \& Gerbing, D. A. (1988). Structural equation modeling in practice: A review and recommended two-step approach. Psychological Bulletin, 103(3), 411-423.

Anderson, J. C., \& Narus, J. A. (1990, January). A model of distributor firm and manufacturer firm working partnerships. Journal of Marketing, 54, 42-58.

Axelrod, R. (1984). The evolution of cooperation. New York: Basic Books.

Ballantyne, D. (1997). Internal networks for internal marketing. Journal of Marketing Management, 13, 343-366.

Barclay, D. W. (1991, May). Interdepartmental conflict in organizational buying: The impact of organizational context. Journal of Marketing Research, 22, 145-159.

Baron, R. (1991). Positive effects of conflict: A cognitive perspective. Employee Response and Rights Journal, 4(1), 25-36.

Blau, P. M. (1964). Exchange and power in social life. New York: John Wiley and Sons. 
Carnevale, P. J., \& Probst, T. M. (1998). Social values and social conflict in creative problem solving and categorization. Journal of Personality and Social Psychology, 74, 13001309.

Chin, W. W. (1998). The partial least square approach to structural equation modeling. In G. A. Marcoulides (Ed.), Modern Methods for Business Research. Mahwah, NJ: Lawrence Erlbaum Associates Publishers, 295-336.

Cooper, R. G. (1979, Summer). The dimensions of industrial new product success and failure. Journal of Marketing, 43, 93-103.

Cooper, R. G. (1996). Overhauling the new product process. Industrial Marketing Management, 25, 465-482.

Cosier, R. A. (1978). The effects of three potential aids for making strategic decisions on predictions accuracy. Organizational Behavior and Human Performance, (22), 295306.

Cosier, R. A., \& Schwenk, C. (1990). Agreement and thinking alike: ingredients for poor decisions. Academy of Management Executive, 4(1), 69-74.

Crawford, C. M., \& DiBenedetto, A. (2003). New Products Management. New York: McGraw-Hill Irwin. 
Daft, R. L., \& Lengel, R. H. (1984). Information richness: A new approach to managerial behavior and organization design. Research in Organizational Behaviour, 6, 191-233.

Daft, R. L., \& Weick, K. E. (1984). Toward a model of organizations as interpretation systems. Academy of Management Review, 9(2), 284-295.

Dawes, P. L. \& Massey, G. R. (2005). Antecedents of conflict in marketing’s cross-functional relationship with sales. European Journal of Marketing, 39, Number 11-12, 13271344.

De Dreu, C., \& Weingart, L. R. (2003). Task versus relationship conflict, team performance, and team member satisfaction: A meta analysis. Journal of Applied Psychology, 88(4), 741-749.

Dewsnap, B., \& Jobber, D. (2000, Spring). The sales-marketing interface in consumer packaged-goods companies: A conceptual framework. Journal of Personal Selling and Sales Management, 20, 109-119.

Diamantopoulos, A., \& Winklhofer, H. M. (2001, May). Index construction with formative indicators: An alternative to scale development. Journal of Marketing Research, 38, 269-277.

Dougherty, D. (1992). Interpretive barriers to successful product innovation in large firms. Organization Science, 3(2), 179-202. 
Filley, A. (1970, Fall). Committee management: Guidelines from social science research. California Management Review, 13, 13-21.

Fisher, R. J., Maltz, E., \& Jaworski, B. J. (1997, July). Enhancing communication between marketing and engineering: The moderating role of relative functional identification. Journal of Marketing, 61, 54-70.

Fornell, C., \& Bookstein, F. L. (1982, November). Two structural equations models: LISREL and PLS applied to consumer exit-voice theory. Journal of Marketing Research, 18, 39-50.

Fornell, C., \& Larcker, D. F. (1981, February). Evaluating structural equation models with unobservable variables and measurement error. Journal of Marketing Research, 18, 39-50.

Galbraith, J. (1977). Organizational design. Reading, MA: Addison-Wesley.

Gerbing, D. W., \& Anderson, J. C. (1988, May). An updated paradigm for scale development incorporating unidimensionality and its assessment. Journal of Marketing Research, 25, 186-192

Gupta, A. K., Raj, S. P., \& Wilemon, D. (1986, April). A model for studying the R\&D-marketing interface in the product innovation process. Journal of Marketing, 50, 7-17. 
Gupta, A. K., \& Wilemon, D. (1988). The credibility-cooperation connection at the R\&Dmarketing interface. Journal of Product Innovation Management, 5, 20-31.

Homburg, C., Workman, J. P. Jr., \& Krohmer, H. (1999, April). Marketing’s influence within the firm. Journal of Marketing, 63, 1-17.

Houston, M. B., Walker, B. A., \& Hutt, M. D., Reingen P. H. (2001, April). Cross-unit competition for a market charter: The enduring influence of structure. Journal of Marketing, 5, 19-34.

Hulland, J. (1999). Use of partial least squares (PLS) in strategic management research: A review of four recent studies. Strategic Management Journal, 20, 195-204.

Jablin, F. M. (1979). Superior-subordinate communication: The state of the art. Psychological Bulletin, 86, 1201-1222.

Jassawalla, A. R., \& Sashittal, H. C. (1998). An examination of collaboration in high-technology new product development processes. Journal of Product Innovation Management, 15, 237-254.

Jaworski, B. J., \& Kohli, A. K. (1993). Market orientation: Antecedents and consequences. Journal of Marketing, 57(2), 53-70.

Jehn, K. A. (1995). A multimethod examination of the benefits and detriments of intragroup conflict. Administrative Science Quarterly,40(2), 265-282. 
Jehn, K. A. (1997). A qualitative analysis of conflict types and dimensions in organizational groups. Administrative Science Quarterly,42(3), 530-557.

Johlke, M. C., Duhan, D. F., Howell, R. D., \& Wilkes, R.W. (2000). An integrated model of sales managers’ communication practices. Journal of the Academy of Marketing Science, 28(2), 263-277.

Johnson. J. D. (1993). Organizational communication structure. Norwood, NJ: Ablex.

Kohli, A. K., \& Jaworski, B. J. (1990 April). Market orientation: the construct, research propositions, and managerial implications. Journal of Marketing, 54, 1-18.

Maltz, E. (1996). An enhanced framework for improving cooperation between marketing and other functions: The differential role of integrating mechanisms. Journal of MarketFocused Management, 2, 83-98.

Maltz, E., \& Kohli, A. K. (1996, February). Market intelligence dissemination across functional boundaries. Journal of Marketing Research, 33, 47-61.

Maltz, E., \& Kohli, A. K. (2000). Reducing marketing's conflict with other functions: The differential aspects of integrating mechanisms. Journal of the Academy of Marketing Science, 28(4), 479-492.

March, J. G., \& Simon, H. A. (1958). Organizations. New York: Wiley. 
Menon, A., Bharadwaj, S. G., \& Howell, R. (1996). The quality and effectiveness of marketing strategy: Effects of functional and dysfunctional conflict in intraorganizational relationships. Journal of the Academy of Marketing Science, 24(4), 299-313.

Menon, A., Bharadwaj, S. G, Adidam, P. T., \& Edison, S. W. (1999, April). Antecedents and consequences of marketing strategy making: A model and test. Journal of Marketing, 63, 18-40.

Menon, A., \& Varadarajan, P. R. (1992, October). A model of marketing knowledge use within firms. Journal of Marketing, 56, 53-71.

Moenaert, R. K., DeMeyer, A., \& Souder, W. E., \& Deschoolmeester, D. (1992). Information styles of marketing and R\&D personnel during technological product innovation projects. R\&D Management, 22(1), 21-39.

Moenaert, R. K., Souder, W. E., DeMeyer, A., \& Deschoolmeester, D. (1994, January). R\&Dmarketing integration mechanisms, communication flows, and innovation success. Journal of Product Innovation Management, 11, 31-45.

Mohr, J. J., Fisher, R. J., \& Nevin, J. R. (1996, July). Collaborative communication in interfirm relationships: Moderating effects of integration and control. Journal of Marketing, 60, 103-115. 
Mohr, J. J., \& Nevin, J. R. (1990, October). Communication strategies in marketing channels: A theoretical perspective. Journal of Marketing, 50, 36-51.

Moorman, C., Deshpandé, R., \& Zaltman, G. (1993, January). Factors affecting trust in market research relationships. Journal of Marketing, 57, 81-101.

Morgan, N. A., \& Piercy, N. F. (1998). Interactions between marketing and quality at the SBU level: Influences and outcomes. Journal of the Academy of Marketing Science, 26(3), 190-208.

Morgan, R. M., \& Hunt, S. D. (1994, July). The commitment-trust theory of relationship marketing. Journal of Marketing, 58, 20-38.

Pondy, L. R. (1967, September). Organizational conflict: Concepts and models. Administrative Science Quarterly, 12, 296-320.

Porter, M. E. (1985). Competitive advantage. New York: The Free Press.

Reid, D. A., Pullins, E. B., Plank, R. E., \& Buehrer, R. E. (2004). Measuring buyers' perception of conflict in business-to-business sales interactions. Journal of Business and Industrial Marketing, 19(4), 236-249.

Robbins, S. P. (1990). Organization theory. Englewood Cliffs, NJ: Prentice-Hall. 
Ruekert, R. W., \& Walker, O. C. (1987a, January). Marketing's interaction with other functional units: A conceptual framework and empirical evidence. Journal of Marketing, 51, 1-19.

Ruekert, R. W., \& Walker, O. C. (1987b, May-June). Interactions between marketing and R\&D departments in implementing different business strategies. Strategic Management Journal, 8, 233-248.

Ryals, L., \& Payne, A. (2001). Customer relationship management in financial services: Towards information-enabled relationship marketing. Journal of Strategic Marketing, 9, 3-27.

Schwenk, C. (1989, May-June). A meta-analysis on the comparative effectiveness of devil's advocacy and dialectical enquiry. Strategic Management Journal,10, 303-306.

Smith, B. J., \& Barclay, D. W. (1997, January). The effects of organizational differences and trust on the effectiveness of selling partner relationships. Journal of Marketing, 61, 321.

Souder, W. E. (1981). Disharmony between R\&D and marketing. Industrial Marketing Management, 10, 67-73.

Souder, W. E., \& Moenaert, R. K. (1992). Integrating marketing and R\&D personnel within innovation projects: an information uncertainty model. Journal of Management Studies, 29(4), 485-512. 
Strahle, W. M., Spiro, R. L., \& Acito, F. (1996, Winter). Marketing and sales: strategic alignment and functional implementation. Journal of Personal Selling and Sales Management, 16, 1-20.

Thomas, K. (1990). Conflict and negotiation processes in organizations. In M. D. Dunnette (Ed.), Handbook of Industrial and Organizational Psychology. Palo Alto, CA: Consulting Psychological Press.

Tjosvold, D. (1985, Fall-Winter). Implications of controversy research in management. Journal of Management, 11, 21-37.

Van de Ven, A. (1976, October). On the nature, formation, and maintenance of relations among organizations. Academy of Management Review, 4, 24-36.

Wheelwright, S. C., \& Clark, K. B. (1992). Revolutionizing product development. New York: The Free Press.

Winer, R. S. (2001, Summer). A framework for customer relationship management. California Management Review, 43(4), 89-105.

Zillman, D. (1988). Cognition-excitation interdependencies and aggressive behavior. Aggressive Behavior, 14, 51-64.

Zirger, B. J., \& Maidique, M. A. (1990, July). A model of new product development: An empirical test. Management Science, 36(7), 867-883. 